\title{
Small-molecule Bcl-2 inhibitors sensitise tumour cells to immune-mediated destruction
}

\author{
JD Lickliter ${ }^{*, 1,2}$, J Cox', J McCarron', NR Martinez', CW Schmidt', H Lin', M Nieda ${ }^{3}$ and AJ Nicol ${ }^{4}$ \\ 'Clive Berghofer Cancer Research Centre, Queensland Institute of Medical Research, Herston, Queensland 4029, Australia; ${ }^{2}$ Department of Medical \\ Oncology, Royal Brisbane and Women's Hospital, Herston, Queensland 4029, Australia; ${ }^{3}$ School of Medicine, Yokohama City University, Yokohama, \\ Japan; ${ }^{4}$ University of Queensland Centre for Immune and Targeted Therapy, Greenslopes Private Hospital, Greenslopes, Queensland 4I 20, Australia
}

The cytotoxic effects of anticancer immune cells are mediated by perforin/granzyme-B, Fas ligand and tumour necrosis factor-related apoptosis-inducing ligand (TRAIL), and therefore depend on intact apoptotic responses in target tumour cells. As killing by all three of these mechanisms is blocked by the frequently overexpressed antiapoptotic oncoprotein $\mathrm{Bcl}-2$, we hypothesised that coexposure to a Bcl-2 inhibitor might enhance anticancer immune responses. We evaluated this in U937 lymphoma cells, and A02 melanoma cells, which both show strong Bcl-2 expression. $\mathrm{V} \alpha 24^{+} \mathrm{V} \beta 1 \mathrm{I}^{+}$natural killer $\mathrm{T}$ (NKT) cells expanded from peripheral blood of normal donors ( $n=3$ ) were coincubated with PKH26-labelled U937 cells, and cytotoxicity was determined by flow cytometry after annexinV-FITC and 7-AAD staining. In all cases, addition of the HAI4-I small-molecule Bcl-2 inhibitor to the cocultures significantly increased apoptosis in the target $U 937$ cells. Using a similar assay, killing of A02 cells by the cytotoxic T-lymphocyte clone IH3 was shown to be amplified by coexposure to the potent small-molecule Bcl-2 inhibitor ABT-737. Experiments with immune effectors preincubated with concanamycin-A suggested that sensitisation to perforin/granzyme-B may underlie enhanced target-cell killing observed in the presence of $\mathrm{Bcl}-2$ inhibitors. We conclude that immune destruction of malignant cells can be amplified by molecular interventions that overcome $\mathrm{Bcl}-2$-mediated resistance to apoptosis.

British Journal of Cancer (2007) 96, 600-608. doi: I0.1038/sj.bjc.6603599 www.bjcancer.com

(c) 2007 Cancer Research UK

Keywords: Bcl-2 inhibitor; cancer immunotherapy; ABT-737; HAI4-I; NKT cells

Anticancer agents such as radiation therapy and chemotherapy kill tumour cells largely by inducing programmed cell death or apoptosis. This is also true for anticancer immune responses, where apoptosis is triggered by the mechanisms including perforin/granzyme-B, Fas ligand (FasL) and tumour necrosis factor-related apoptosis-inducing ligand (TRAIL). However, tumours frequently overexpress genes that inhibit apoptosis and which therefore contribute to treatment resistance (Cory et al, 1999). The Bcl-2 family of antiapoptosis mitochondrial proteins (which also includes Bcl- $\mathrm{x}_{\mathrm{L}}$ and Mcl-1) is an important example of this. These proteins are potent inhibitors of cell death, and high expression levels are observed in many cancers (Adams and Cory, 1998; Reed, 1999). Bcl-2 itself is highly expressed in the majority of cases of acute leukaemia, approximately $50 \%$ of diffuse large B-cell lymphomas and up to $90 \%$ of malignant melanomas (Banker et al, 1997; Jansen et al, 1998; Campos et al, 1999; Skinnider et al, 1999). Forced expression of Bcl-2 results in resistance to a variety of proapoptotic stimuli, including growth factor withdrawal, cytotoxic chemotherapy and radiation, and there is some evidence that Bcl-2 also promotes resistance to anticancer immune responses. For example, transfection-mediated overexpression of $\mathrm{Bcl}-2$ rendered Jurkat leukaemia cells refractory to killing by a cytotoxic

*Correspondence: Dr JD Lickliter, Department of Medical Oncology, Royal Brisbane and Women's Hospital, Butterfield Street, Herston, Queensland 4029, Australia; E-mail: Jason_Lickliter@health.qld.gov.au Revised I4 December 2006; accepted 19 December 2006
T-cell clone (Torigoe et al, 1994). In other studies, enforced Bcl-2 expression was shown to inhibit several key mechanisms of immune killing, including those initiated by granzyme-B, FasL and TRAIL (Pinkoski et al, 2001; Raisova et al, 2001; Fulda et al, 2002; Guseva et al, 2002; Velthuis et al, 2002).

Interfering with the expression or function of Bcl-2 might be an effective anticancer strategy. Antisense oligonucleotides that decrease Bcl-2 expression caused direct tumour suppression and increased sensitivity to cytotoxic chemotherapy in preclinical models (Cotter et al, 1994; Jansen et al, 1998). However, Bcl-2 antisense therapy had limited activity when tested in clinical trials, potentially owing to poor access to the intracellular compartment and inadequate reduction in Bcl-2 expression levels (Waters et al, 2000; Yuen and Sikic, 2000; Morris et al, 2002). More recently, small molecules that target the $\mathrm{BH} 3$-domain-binding site of $\mathrm{Bcl}-2$ have been developed as Bcl-2 inhibitors (Wang et al, 2000; Oltersdorf et al, 2005). It is hypothesised that these agents displace proapoptotic BH3-only proteins (e.g., Bid and Bim) from their binding groove on Bcl-2, thus promoting interaction with Bax and Bak, and transduction of an apoptotic signal (Oltersdorf et al, 2005). One of these compounds - ethyl 2-amino-6bromo-4-(1-cyano-2-ethoxy-2-oxoethyl)-4H-chromene-3-carboxylate (designated HA14-1) - directly triggered apoptosis in Bcl-2expressing leukaemia and lymphoma cell lines, and also enhanced the cytotoxicity of the antileukaemia drug cytarabine (Wang et al, 2000; Lickliter et al, 2003). A more-recently developed compound, ABT-737, bound to Bcl-2 and Bcl- $\mathrm{x}_{\mathrm{L}}$ with extremely high affinity 
(inhibitory constant $K_{\mathrm{i}} \leqslant 1 \mathrm{nM}$ ), and exhibited significant in vitro and in vivo activity in preclinical models of follicular lymphoma and small-cell lung cancer (Oltersdorf et al, 2005). In addition, ABT-737-induced apoptosis in primary patient-derived samples of follicular lymphoma cells and chronic lymphocytic leukaemia cells.

Inhibition of Bcl-2 may be of particular benefit in combination with other strategies that promote apoptosis of malignant cells. As Bcl-2 overexpression may protect malignant cells from antitumour immune responses, we investigated whether coexposure to both Bcl-2 inhibitor and activated immune cells could increase tumourcell killing. This hypothesis was examined in two models of anticancer immunotherapy. The first utilised human $\mathrm{V} \alpha 24^{+}$ $\mathrm{V} \beta 11^{+} \mathrm{T}$-cell receptor (TCR) expressing natural killer $\mathrm{T}$ cells (NKT cells) as the immune effector cells (Nieda et al, 1999). Natural killer $\mathrm{T}$ cells have been shown to exert significant in vitro and in vivo antitumour activity against a variety of solid malignancies and myeloid leukaemia (Kikuchi et al, 2001; Nieda et al, 2001). Relevant to their practical application in human immune therapies, they can be potently activated by agents such as $\alpha$-galactosylceramide (KRN7000). We chose the U937 lymphoma cell line as the NKT-cell target (Nicol et al, 2000; Takahashi et al, 2000) because U937 cells express high levels of antiapoptotic Bcl-2 (Lickliter et al, 2003). The second model is also relevant to clinical immunotherapy, with the use of A02 human melanoma cells as the target and a Melan-A/MART-1-specific cytotoxic T-lymphocyte (CTL) clone as effector cells. Like U937 cells, A02 cells strongly express $\mathrm{Bcl}-2$ and were therefore suitable for investigating the combined effects of immune attack and exposure to a Bcl-2 inhibitor.

\section{MATERIALS AND METHODS}

\section{NKT cells}

Peripheral blood mononuclear cells (PBMC) were separated from peripheral blood of healthy adult volunteers $(n=3)$ by density centifugation over Ficoll-Paque PLUS (Amersham Biosciences, Uppsala, Sweden). Informed consent was obtained from donors before blood collection, and the research was approved by the Human Research Ethics Committees of the Royal Brisbane and Women's Hospital, and Queensland Institute of Medical Research. Following isolation, PBMC were resuspended in AIM-V medium (Gibco BRL, Melbourne, Australia) supplemented with 10\% foetal calf serum (Gibco BRL), penicillin/streptomycin, $100 \mathrm{ng} \mathrm{ml}^{-1}$ KRN7000 (Kirin Brewery, Japan) and $10 \mathrm{U} \mathrm{ml}^{-1}$ interleukin-2 (IL-2; R\&D Systems, Sydney, Australia), and incubated at $37^{\circ} \mathrm{C}$ in a $5 \% \mathrm{CO}_{2}$ atmosphere. After 7 days, the activated and expanded NKT cells were positively selected using an anti-V $\alpha 24$ monoclonal antibody (Beckman Coulter, Sydney, Australia) and magnetic beads (miniMACS system, Miltenyi Biotec, Sydney, Australia). The frequency of NKT cells at specific points during their expansion and purification was assessed with an XL-MCL flow cytometer (Beckman Coulter) after staining with anti-V $\alpha 24$-fluorescein isothiocyanate (FITC), anti-V $\beta 11$-phycoerythrin (PE) and antiCD3-phycocyanin 5 (PC5) antibodies (Beckman Coulter). Results were analysed with EXPO32 software (Beckman Coulter).

\section{Bcl-2 expression in target cells}

The A02 melanoma cell line was derived at the Queensland Institute of Medical Research from a mechanically disaggregated fresh surgical melanoma specimen taken from an HLA-A0201 positive patient. A02 cells and U937 lymphoma cells were grown at $37^{\circ} \mathrm{C}$ in a $5 \% \mathrm{CO}_{2}$ atmosphere using RPMI 1640 medium supplemented with $10 \%$ foetal calf serum, penicillin and streptomycin. To determine Bcl-2 expression in the U937 cells, aliquots of $5 \times 10^{5}$ cells were fixed and permeabilised using the IntraPrep kit
(Immunotech, France) according to the manufacturer's instructions. Cells were then stained with $5 \mu \mathrm{l}$ of FITC-conjugated antiBcl-2 monoclonal antibody (clone 124; Dako, Carpinteria, CA, USA) or an $I_{g} G_{1}$ isotype control (BD Biosciences, San Jose, CA, USA), and examined with an XL-MCL flow cytometer. Results were analysed using Summit version 3.1 software (Cytomation Inc. Fort Collins, CO, USA). Bcl-2 expression in the A02 cells was determined by Western blotting. Cells were resuspended in lysis buffer ( $50 \mathrm{~mm}$ Tris $\mathrm{pH}$ 7.6, $250 \mathrm{~mm} \mathrm{NaCl}, 5 \mathrm{~mm}$ EDTA pH 8, $50 \mathrm{~mm}$ $\mathrm{NaF}$ and $50 \mathrm{~mm}$ PMSF) and centrifuged. The supernatant was then collected and $100 \mu \mathrm{g}$ of protein was separated by SDS-polyacrylamide gel electrophoresis and electroblotted onto a PVDF membrane (Bio-Rad). The membrane was incubated with antiBcl-2 monoclonal antibody (clone 124, Dako) at a dilution of $1: 200$, followed by a secondary horseradish peroxidase-conjugated rabbit anti-mouse IgG antibody (Dako) at a dilution of $1: 5000$. Binding of antibodies was visualised by enhanced chemiluminescence (ECL; Amersham Biosciences). To confirm even loading of the gel lanes with protein, the membrane was re-probed with an anti- $\beta$-actin antibody (clone AC-15; Sigma Aldrich, Sydney, Australia).

\section{Preparation of compounds}

The HA14-1 small-molecule inhibitor of Bcl-2 was purchased from Maybridge (Tintagel, UK; product code BTB02933). The compound was dissolved in dimethyl sulphoxide (DMSO), diluted in cell-culture medium to a concentration of $500 \mu \mathrm{M}$ and stored at $-70^{\circ} \mathrm{C}$. A fresh aliquot was thawed and used immediately in each experiment. ABT-737 (a gift from Abbott Laboratories, Abbott Park, IL, USA) was dissolved in DMSO and stored at $-20^{\circ} \mathrm{C}$.

\section{Cytotoxicity assays}

Purified NKT cells were seeded into round bottom 96-well plates at a density of $2 \times 10^{5}$ cells well $^{-1}$ in a final volume of $200 \mu$ l of AIM-V medium $/ 10 \%$ foetal calf serum. U937 cells were washed in serumfree medium and stained with the membrane dye PKH26 (Sigma), according to the manufacturer's instructions. PKH26-labelled U937 cells were then added to wells containing NKT cells for an effector:target (E:T) ratio of 20:1 (donor 1) or 10:1 (donors 2 and 3 ), and coincubated at $37^{\circ} \mathrm{C}$ in $5 \% \mathrm{CO}_{2}$ for a total of $4 \mathrm{~h}$. After the initial $1 \mathrm{~h}$ of incubation, either $25 \mu \mathrm{m}$ of the HA14-1 Bcl-2 inhibitor or DMSO vehicle alone was added to the coculture wells and to control wells containing U937 cells alone. To evaluate for apoptosis, cells were washed in annexin-V-binding buffer $(10 \mathrm{~mm}$ HEPES pH 7.4, $140 \mathrm{~mm} \mathrm{NaCl}$ and $2.5 \mathrm{mM} \mathrm{CaCl}_{2}$ ), and stained with $5 \mu \mathrm{l}$ of annexin-V-FITC (BD Biosciences) and $10 \mu \mathrm{l}(0.5 \mu \mathrm{g})$ of 7amino-actinomycin D (7-AAD; BD Pharmingen). A minimum of 10000 events per sample was then acquired on an XL-MCL flow cytometer and results were analysed using EXPO32 or Summit version 3.1 software. U937-cell viability was defined as the percentage of $\mathrm{PKH} 26^{+}$cells that was negative for annexin-V.

The $1 \mathrm{H} 3$ antimelanoma CTL clone was derived from PBMC isolated from an HLA-A0201 positive melanoma patient and recognises the Melan-A/MART-1 melanoma antigen. Cryopreserved $1 \mathrm{H} 3$ cells were thawed and stimulated at 20000 cells well $^{-1}$ in a U-bottom 96-well plate containing irradiated (3000 rad) feeder cells $\left(1 \times 10^{5}\right.$ allogenic PBMC and $2 \times 10^{4}$ cells well $^{-1}$ BLCL). Stimulatory medium consisted of RPMI 1640 containing 5\% pooled human sera, $100 \mathrm{U} \mathrm{ml}^{-1}$ IL-2 and $1 \mu \mathrm{g} \mathrm{ml}^{-1}$ phytohemagglutinin-L (PHA-L). After 7 days, half of the medium volume was replaced with medium containing $5 \%$ pooled human sera and $100 \mathrm{U} \mathrm{ml}^{-1} \mathrm{IL}-2$ without PHA-L. For all experiments, clones were used at least 7 days after the start of expansion. A02 melanoma cells were de-adhered from tissue culture flasks using trypsin without EDTA and stained with PKH26 dye (Sigma), according to the manufacturer's instructions. The labelled A02 cells were then added to U-bottom 96-well plate containing $1 \mathrm{H} 3$ cells to achieve an 
$\mathrm{E}: \mathrm{T}$ ratio of $0.2: 1$, and the cocultures were incubated at $37^{\circ} \mathrm{C}$ in $5 \% \mathrm{CO}_{2}$ for a total of 4 or $8 \mathrm{~h}$. After the initial $1 \mathrm{~h}$ of incubation, either $1 \mu \mathrm{M}$ of ABT-737 or the corresponding amount of DMSO vehicle alone was added to the coculture wells, and to control wells containing A02 cells alone. Apoptosis was subsequently evaluated by annexin- $\mathrm{V}$ and 7-AAD staining (as described above), followed by analysis with a FACSCalibur flow cytometer and CellQuest Pro version 5.2 software (BD Biosciences). At least 10000 events were acquired per sample.

\section{Inhibition of perforin/granzyme-B}

To investigate the role of the perforin/granzyme-B pathway, immune effector cells were preincubated for $2 \mathrm{~h}$ with the perforin inhibitor concanamycin-A (Sigma) at $100 \mathrm{~nm}$ (NKT cells) or $1000 \mathrm{~nm}$ (1H3 cells), or with the corresponding amount of DMSO vehicle alone (Kataoka et al, 1996). The effector cells were then washed twice with phosphate-buffered saline and used in cytotoxicity assays similar to those described above.

\section{RESULTS}

\section{Expansion and purification of NKT cells}

Freshly isolated PBMC from all normal donors studied contained detectable numbers of NKT cells (Figure 1; Table 1). These numbers markedly increased following 7 days of stimulation with IL-2 and KRN7000, resulting in NKT-cell frequencies of $18-36 \%$ of
A

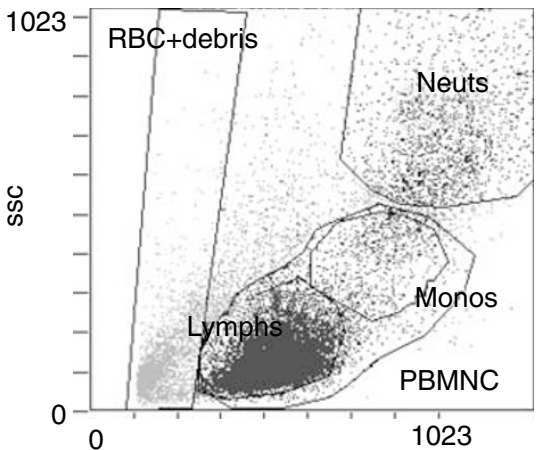

B

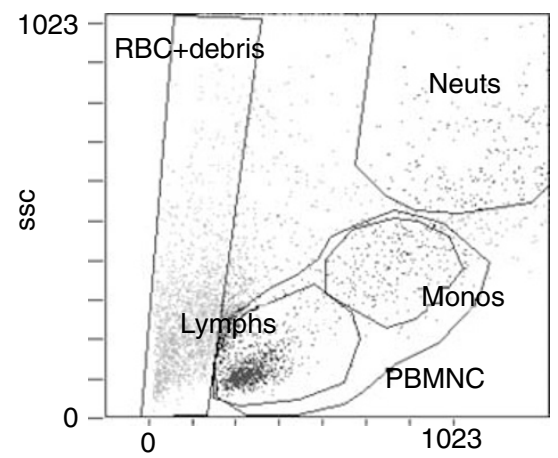

C

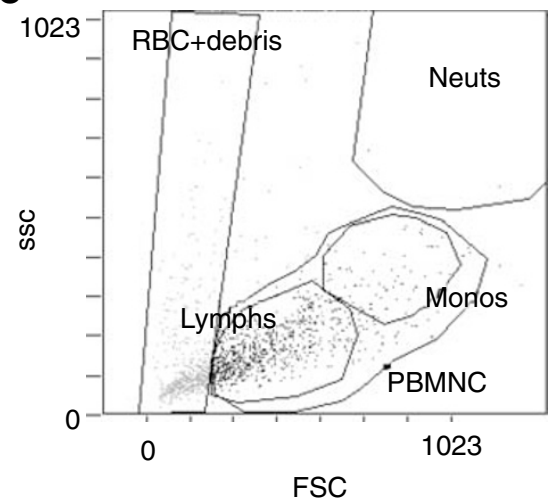

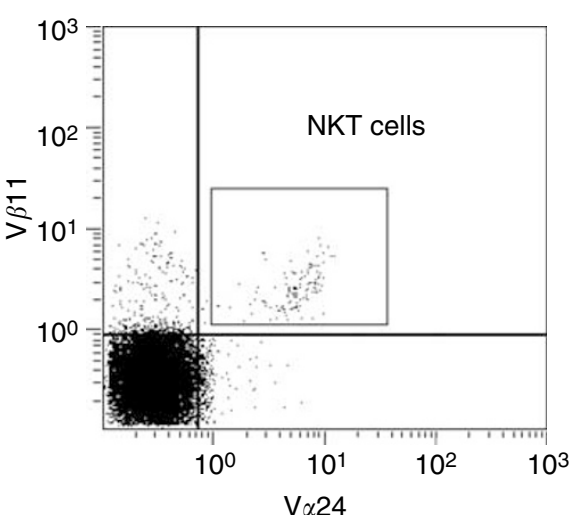
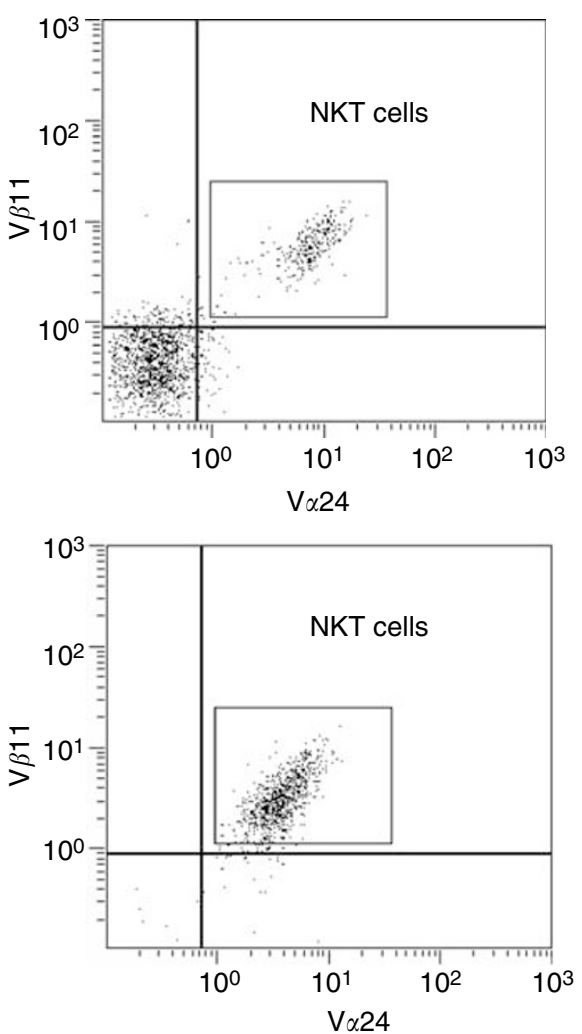

Figure I Expansion and purification of NKT cells from normal donor PBMNC. Typical results before expansion $(\mathbf{A})$, after 7 days of expansion culture (B) and following magnetic separation of $\mathrm{V} \alpha 24^{+}$cells $(\mathbf{C})$ are shown. Cells were stained with anti-V $\alpha 24-\mathrm{FITC}$, anti-V $\beta \mid$ I-PE and anti-CD3-PC5 antibodies, and then analysed by flow cytometry. Right panels were gated on the PBMNC region defined in the left panels, and $\mathrm{V} \alpha 24^{+} \mathrm{V} \beta \mathrm{I}^{+} \mathrm{NKT}$ cells were counted in the region shown. Abbreviations: FSC, forward scatter; SSC, side scatter; RBC + debris, region-containing erythrocytes and debris; Neuts, neutrophils; Monos, monocytes; Lymphs, lymphocytes. 
Table I NKT-cell frequencies in samples from three normal donors, evaluated using the method shown in Figure

\begin{tabular}{lccc}
\hline & Day 0 & Day 7 & Postseparation \\
\hline Donor 1 & 0.1 & 36.1 & 95.7 \\
Donor 2 & 0.5 & 17.9 & 94.5 \\
Donor 3 & 0.1 & 18.9 & 79.0 \\
\hline
\end{tabular}

Results before expansion (Day 0), after 7 days of expansion culture (Day 7) and after magnetic separation of $\mathrm{V} \alpha 24^{+}$cells (postseparation) are shown, expressed as a percentage of total mononuclear cells.

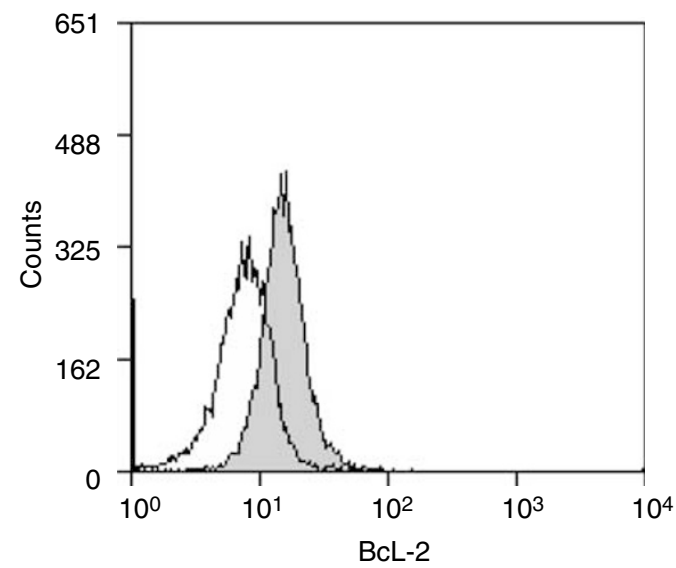

Figure $2 \mathrm{Bcl}-2$ expression in $U 937$ cells. The histogram plot shows flow-cytometry results after intracellular staining of U937 cells with FITCconjugated anti-Bcl-2 antibody (gray plot) or isotype control antibody (open plot)

mononuclear cells. Following magnetic separation, populations of $\mathrm{V} \alpha 24^{+} \mathrm{V} \beta 11^{+}$NKT cells that were $79-96 \%$ pure were obtained. Consistent with an NKT-cell phenotype, these cells were also positive for CD3 (data not shown).

\section{Cytotoxic effects of combined NKT cells and HA14-1 on U937 lymphoma cells}

Bcl-2-expressing U937 lymphoma cells (Figure 2) were coincubated with purified NKT cells from each normal donor. To test the effect of suppressing Bcl-2 function on the susceptibility of U937 cells to NKT-cell cytotoxicity, cocultures were supplemented either with the HA14-1 small-molecule Bcl-2 inhibitor or with vehicle alone. Viability of the U937 target cells was then evaluated with a well-established flow-cytometry technique (Fischer et al, 2002; Lin et al, 2004), as shown in Figure 3. This involved utilising the PKH26 fluorescent membrane dye to distinguish U937 cells from NKT effector cells and FITC-conjugated annexin-V to stain dying cells. Therefore, viable and dying U937 cells were identified as $\mathrm{PKH} 26^{+} /$annexin- $\mathrm{V}^{-}$and $\mathrm{PKH} 26^{+} /$annexin- $\mathrm{V}^{+}$populations, respectively. Figure 3 illustrates that HA14-1 on its own triggered only a low level of cell death at the concentration used in these experiments. Natural killer T cells in the absence of HA14-1 were cytotoxic; however, combined exposure to both NKT cells and the Bcl-2 inhibitor resulted in a significant amplification of cytotoxicity with a corresponding marked increase in annexin- $\mathrm{V}^{+}$U937 cells. As shown in Figure 4, the enhanced cytotoxicity induced by coexposure to HA14-1 was observed in experiments with NKT cells isolated from all three normal donors tested. The mean U937-cell viability in the cocultures decreased from 44.5 to $13.7 \%$ (donor 1 ), 59.1 to $24.6 \%$ (donor 2) and 76.6 to $33.9 \%$ (donor 3 ) with the addition of HA14-1. Compared to the effects of NKT cells alone, combination with the $\mathrm{Bcl}-2$ inhibitor therefore reduced target-cell viability by an additional 56-69\%. Importantly, since HA14-1 on its own reduced the viability of U937 cells by only $9-18 \%$, our results indicate that coexposure to NKT cells and HA14-1 enhanced target-cell destruction in a synergistic fashion.

Inhibition of Bcl-2 with HA14-1 should induce apoptosis rather than primary necrosis. We therefore investigated the mode of U937-cell death in the cocultures by analysing the pattern of 7-AAD staining in $\mathrm{PKH} 26^{+} /$annexin- $\mathrm{V}^{+}$cells. As described previously (Philpott et al, 1996), necrotic cells stain brightly for 7-AAD, whereas apoptotic cells become dimly positive. Figure 5 shows results from a typical coculture experiment after gating on the $\mathrm{PKH} 26^{+}$population. Exposure to NKT cells in the absence of HA14-1 resulted in annexin- $\mathrm{V}^{+}$U937 cells that were 7-AAD negative, 7-AAD dim and 7-AAD bright. Significantly, coexposure to HA14-1 caused a marked increase in the 7-AAD-dim subpopulation, indicating that the increase in U937-cell death was predominantly owing to apoptosis.

\section{CTL killing of melanoma cells is amplified by the ABT-737 Bcl-2 inhibitor}

Figure 6 shows that the A02 melanoma cell line strongly expresses antiapoptotic Bcl-2. The expression level is significantly higher than in K562 cells and is comparable to that in the LK63 acute lymphoblastic leukaemia line, which expresses high levels of the Bcl-2 oncoprotein that influence its survival (Lickliter et al, 2003). We investigated whether inhibiting Bcl-2 in A02 cells with the potent small-molecule inhibitor ABT-737 would sensitise them to destruction by a Melan-A/MART-1-specific antimelanoma CTL line (Figure 7). Effector $1 \mathrm{H} 3$ cells were coincubated with target A02 cells at a low $\mathrm{E}: \mathrm{T}$ ratio $(0.2: 1)$, to better simulate the conditions encountered in vivo in clinical immunotherapy. Target cells were again labelled with PKH26 and wells were supplemented with either ABT-737 at $1 \mu \mathrm{M}$ or vehicle alone after the initial $1 \mathrm{~h}$ of coculture. A proportion of the $\mathrm{PKH} 26^{+}$target cells $(<20 \%)$ was positive for 7-AAD; however, this was not significantly different between control wells containing A02 cells alone and coculture wells supplemented with vehicle alone or ABT-737 (data not shown). This population likely represents A02 cells that sustained mechanical damage at baseline when de-adhered from tissue culture flasks. Flow-cytometry analysis plots were therefore gated on $\mathrm{PKH} 26^{+}$events that were negative for 7-AAD, so as to exclude this background cell death. The proportion of annexin- $\mathrm{V}^{+}$cells in the gated population (indicated as percentages in Figure 7) is a measure of the specific killing of A02 cells by the CTL clone and/or ABT-737. Typical results from one of the three independent experiments are shown in Figure 7. This indicates that either $1 \mathrm{H} 3$ antimelanoma $\mathrm{T}$ cells or the ABT-737 $\mathrm{Bcl}-2$ inhibitor caused significant destruction of the A02 cells on their own. In contrast, when A02 cells were exposed to both CTL and ABT-737, there was a substantial amplification of target-cell killing. In the experiment shown, CTL alone triggered a $9 \%$ increase in A02 cell death over baseline, whereas CTL and ABT-737 induced a $36 \%$ increase. As ABT-737 alone was associated with only a $4 \%$ increase in cytotoxicity, the combined treatment resulted in supraadditive destruction of the melanoma cells. Importantly, the increase in A02 cell death was due to an increase in the annexin- $\mathrm{V}^{+} 7-\mathrm{AAD}^{-}$ subpopulation and therefore specifically to an increase in apoptosis.

\section{Role of perforin/granzyme-B}

We next investigated whether blocking the perforin/granzyme-B effector pathway of immune cells would affect the enhanced targetcell killing associated with coexposure to a Bcl-2 inhibitor. NKT cells from donor 2 were preincubated with either the perforin inhibitor concanamycin-A or vehicle alone, before establishing 
A

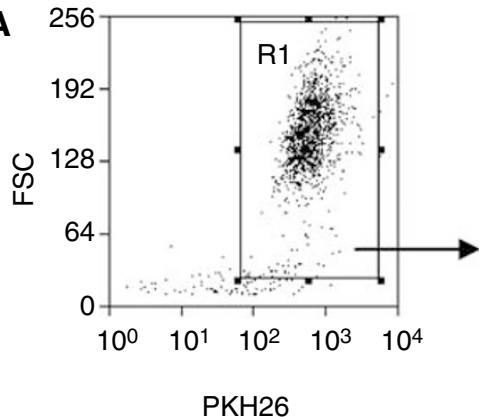

PKH26

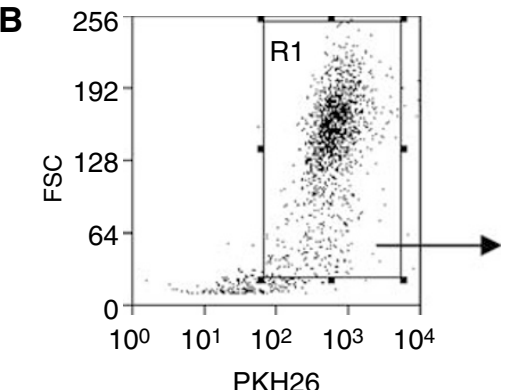

C

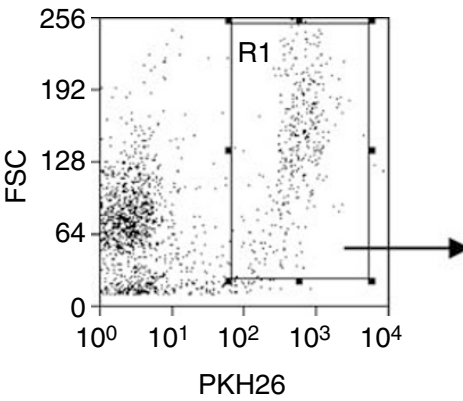

D

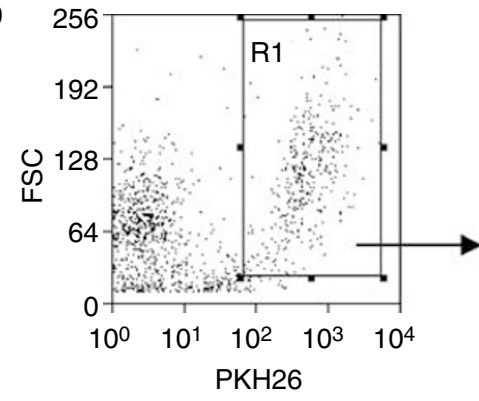

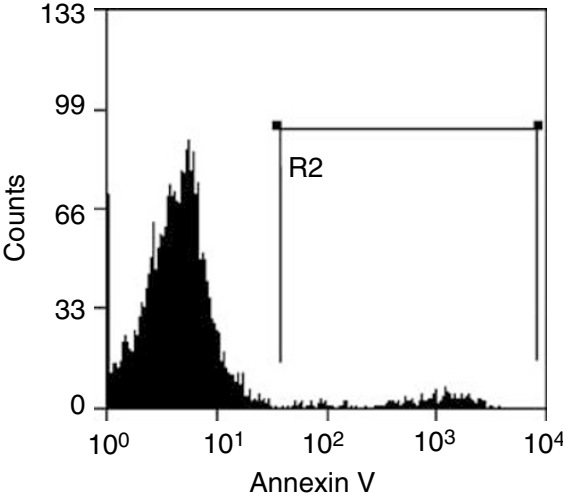
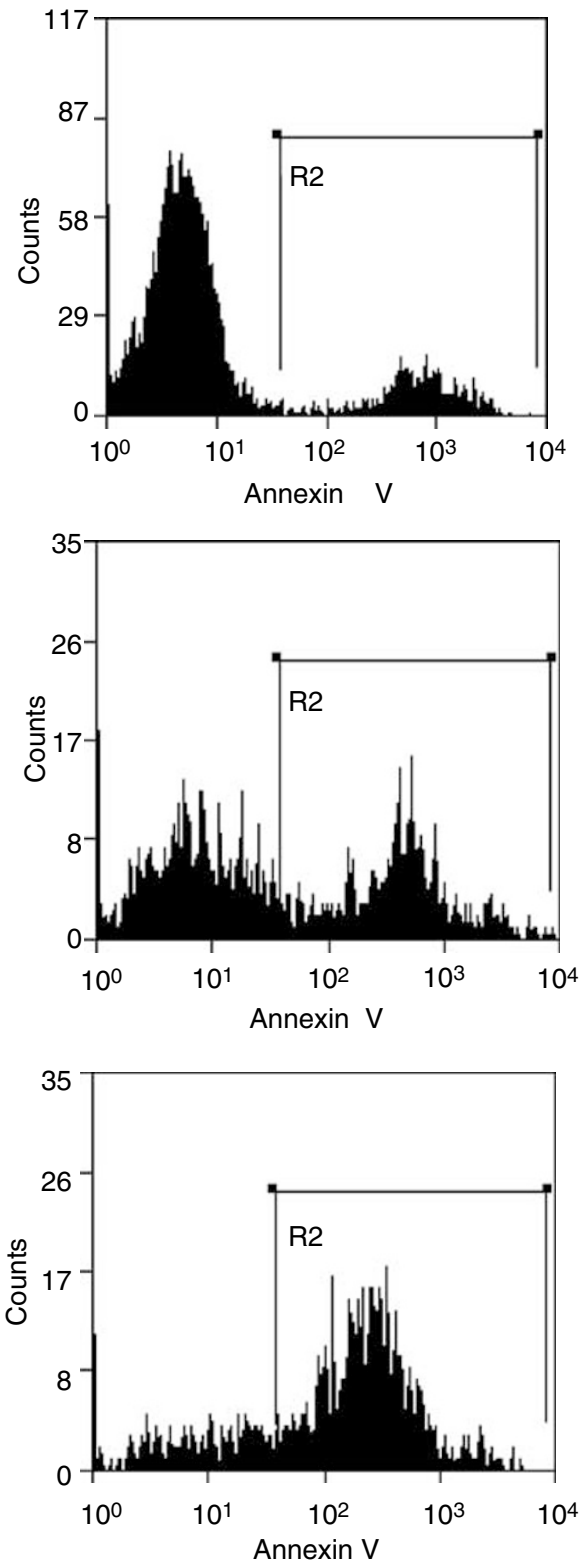

Figure 3 Effect of the HA I4-I Bcl-2 inhibitor on cytotoxicity induced in U937 lymphoma cells by NKT cells. PKH26-labelled U937 cells were coincubated with purified NKT cells at a I0: I effector:target ratio, either with HAI4-I (D) or with vehicle alone (C). U937 cells incubated without NKT cells were also exposed to HAI4-I (B) or vehicle only $(\mathbf{A})$. After $4 \mathrm{~h}$, the cells were stained with annexin-V-FITC and 7-AAD, and then analysed by flow cytometry. The proportion of $\mathrm{U} 937$ target cells undergoing cell death was determined by first gating on $\mathrm{PKH} 26^{+}$cells (region RI, left panels) and then enumerating annexin- $\mathrm{V}^{+}$events (region R2, right panels) in the gated population. 
cocultures with U937 target cells. Typical results from one of two independent experiments are shown in Figure 8 and reveal that inhibition of perforin did not significantly alter NKT-cell killing of U937 cells in the absence of HA14-1. This suggests that the perforin/granzyme-B system did not significantly contribute to the baseline cytotoxicity of NKT cells from this donor against the U937-cell targets. In contrast, the increase in U937-cell death induced by coexposure to HA14-1 was almost completely blocked by preincubation of the NKT cells with concanamycin-A. These

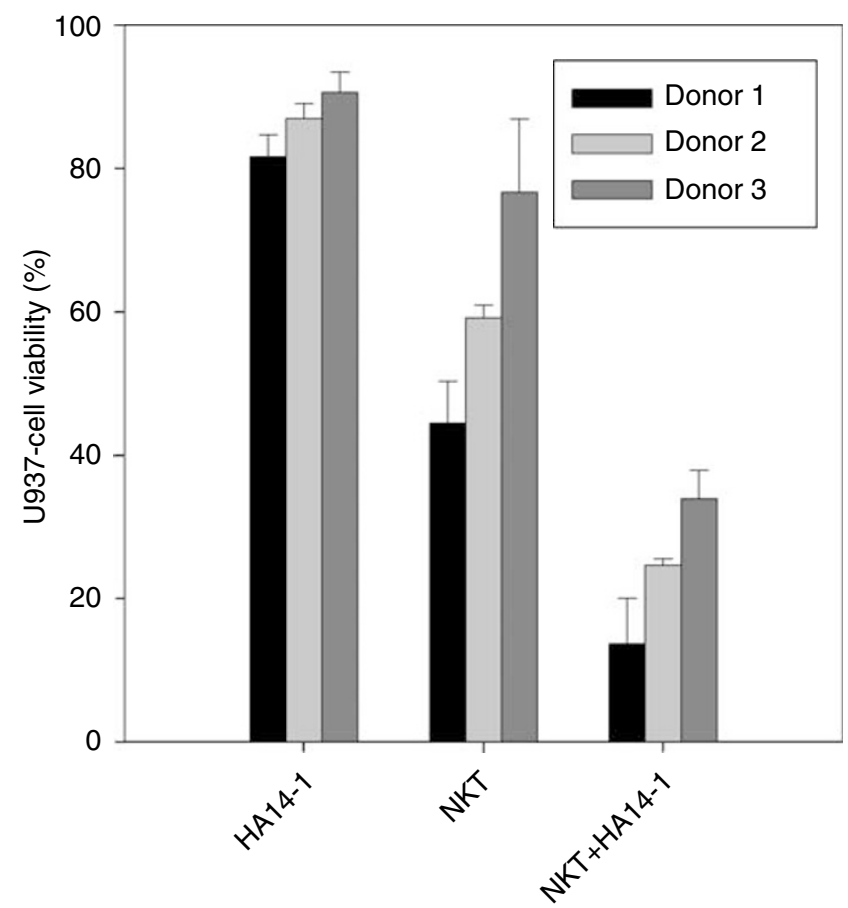

Figure 4 Cytotoxicity of NKT cells from three normal donors in combination with HAI4-I, determined as shown in Figure 3. Bars represent mean U937-cell viability in triplicate assays, normalised to the viability of control cells. Results following exposure to HAI4-I alone (HA|4-I). NKT cells plus DMSO vehicle (NKT) and NKT cells plus HAI4-I (NKT + HAI4I) are shown. Error bars indicate the s.d. results suggest that the perforin/granzyme-B pathway plays an essential role in the amplification of cytotoxicity against U937 cells mediated by HA14-1, at least in the case of NKT cells isolated from donor 2. We also investigated the role of perforin and granzyme-B in the augmentation of $1 \mathrm{H} 3$-cell cytotoxicity against A02 melanoma cells associated with coexposure to the ABT-737 Bcl-2 inhibitor. In this model, inhibition of perforin with concanamycinA almost completely abolished CTL cytotoxicity, both in the presence and absence of ABT-737 (data not shown). This indicates that $1 \mathrm{H} 3$ cells killed their A02 targets almost exclusively via the perforin/granzyme-B pathway. Consequently, the significant increase in killing of A02 cells observed with ABT-737 coexposure potentially reflects a heightened susceptibility to apoptosis induction by granzyme-B.

\section{DISCUSSION}

We investigated the effects of inhibiting the Bcl-2 antiapoptosis oncoprotein on the susceptibility of Bcl-2-overexpressing tumour cells to cytotoxic immune cells. NKT cells derived from three normal donors all showed markedly increased cytotoxicity against Bcl-2-positive U937 lymphoma cells when combined with the HA14-1 small-molecule inhibitor of Bcl-2. In addition, a CTL

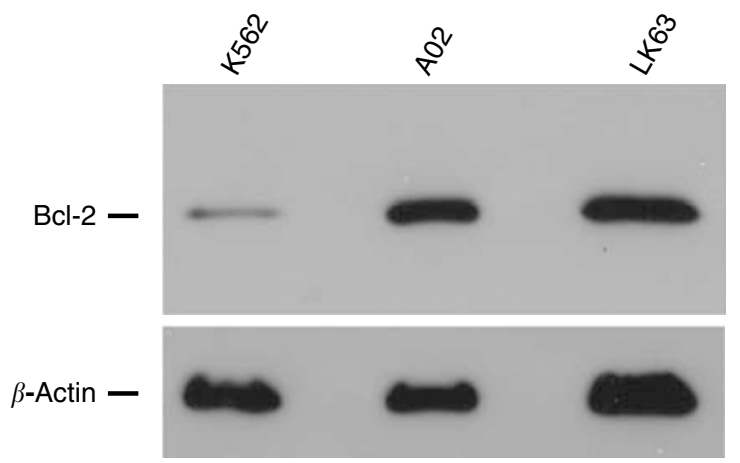

Figure 6 Western blot showing expression of Bcl-2 in A02 melanoma cells compared with that in cells with low expression (K562) and high expression (LK63) levels. The blot was probed with an anti-Bcl-2 monoclonal antibody and subsequently with an anti- $\beta$-actin antibody, as a loading control.
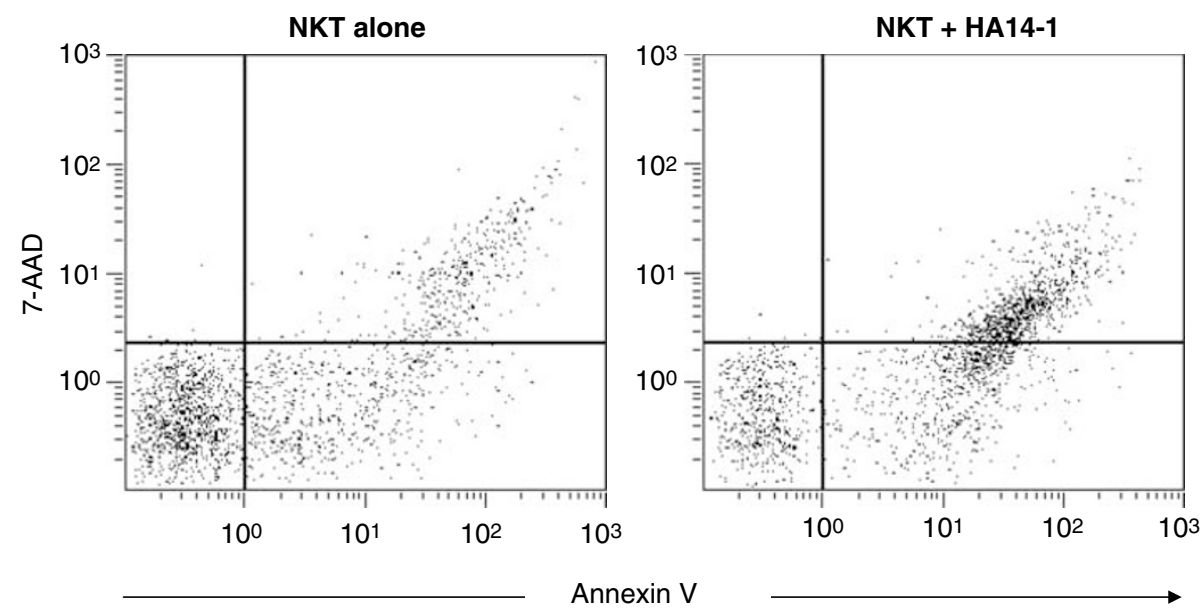

Figure 5 Analysis of 7-AAD staining of U937 target cells. Cocultures of NKT cells and PKH26-labelled U937 cells were stained with annexin-V-FITC and 7-AAD, and then analysed by flow cytometry. Plots gated on PKH26 ${ }^{+}$cells are shown for cocultures supplemented with vehicle only (NKT alone) or with HAI4-I (NKT + HAI4-I). 

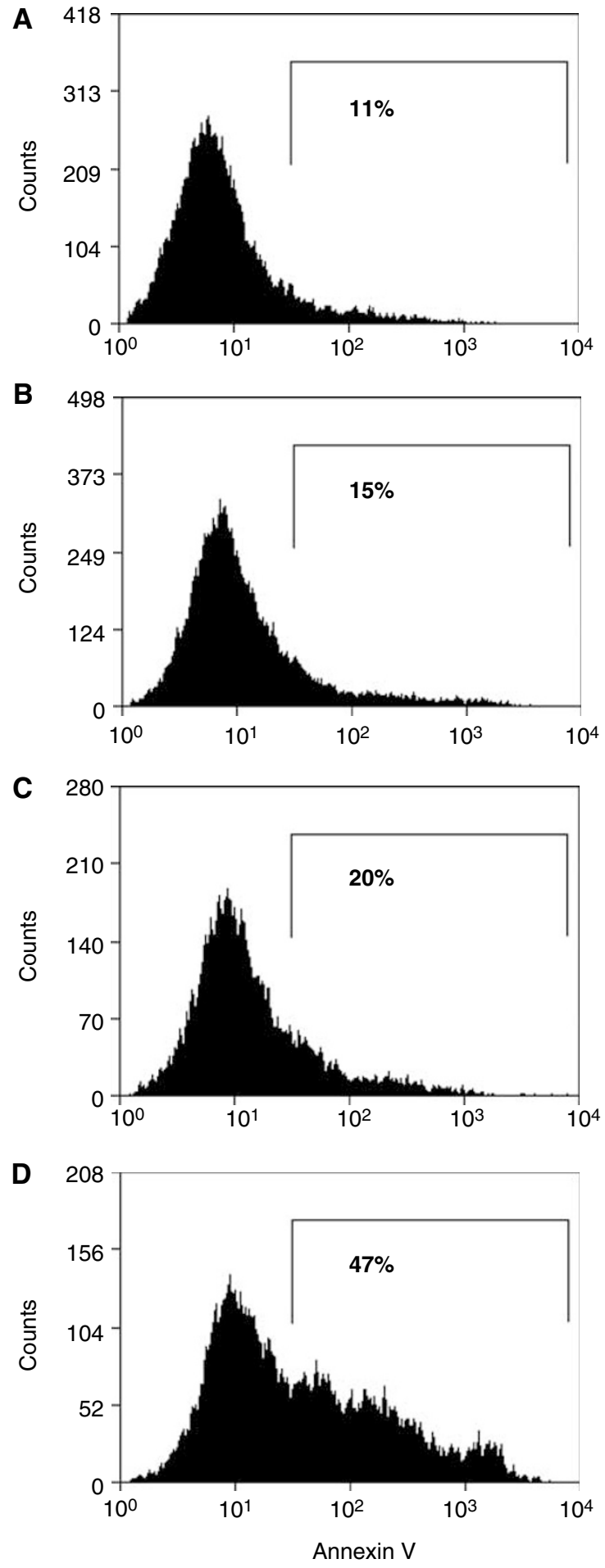

Figure 7 Destruction of A02 melanoma cells by an activated CTL clone is enhanced by coexposure to the small-molecule Bcl-2 inhibitor ABT-737. PKH26-labelled A02 cells were coincubated with the Melan-A/MART-I specific T-cell clone $\mathrm{IH} 3$ at an $\mathrm{E}: \mathrm{T}$ ratio of $0.2: \mathrm{I}$. After I h, either I $\mu$ MABT-737 (D) or vehicle alone (C) was added to the cocultures. Control wells with A02 cells alone were also exposed to I $\mu \mathrm{MABT}-737$ (B) or vehicle only $(\mathbf{A})$. After a total of $4 \mathrm{~h}$, the $\mathrm{A} 02$ target cells were evaluated for cell death by staining with annexin-V-FITC and 7-AAD, followed by flow cytometry analysis. The histograms shown were gated on events positive for PKH26 and negative for 7-AAD, to exclude non-target cells and necrotic target cells. The percentages shown below the markers represent the percentage of annexin- $V^{+}$events and therefore enumerate apoptotic A02 cells.

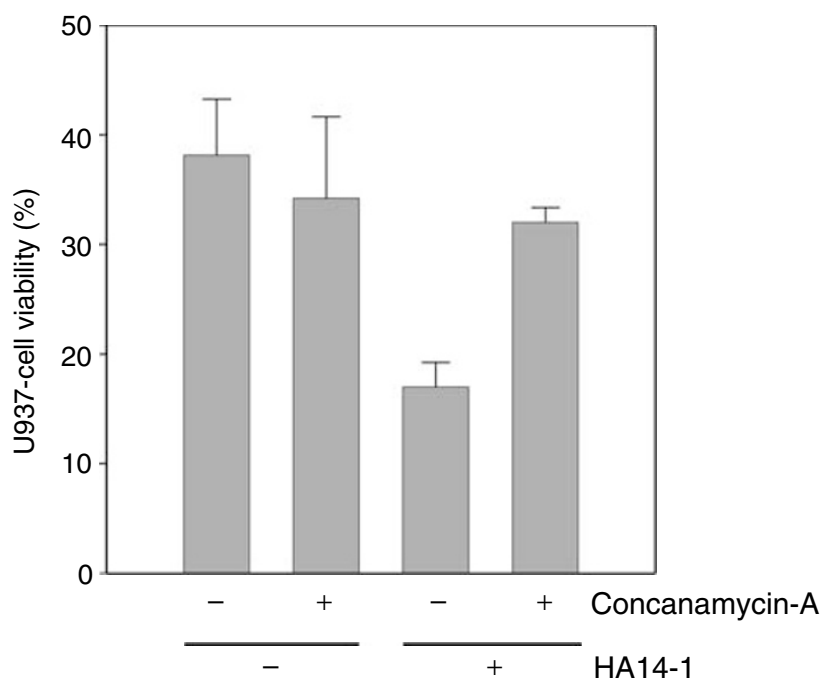

Figure 8 Effect of inhibiting the perforin/granzyme-B pathway. The cytotoxicity of NKT cells preincubated with either concanamycin-A or control medium was assessed in combination with HAI4-I or vehicle only, using the method shown in Figure 3. Bars indicate mean U937-cell viability in triplicate assays and error bars the s.d.

antimelanoma clone specific for Melan-A/MART-1 revealed significantly more killing of Bcl-2-overexpressing A02 melanoma cells in the presence of the potent Bcl-2 inhibitor ABT-737. Consistent with the cellular physiology of $\mathrm{Bcl}-2$ inhibition, target tumour cells were predominantly induced to undergo apoptosis by combined treatment with immune effector cells and a Bcl-2 inhibitor. Our findings therefore support the hypothesis that Bcl-2 expression in the target U937 and A02 cells suppressed the proapoptotic effects of antitumour immune cells, and that inhibition of Bcl-2 can remove this suppression and allow apoptosis of the tumour cells to proceed.

The perforin/granzyme-B system is an important mechanism of CTL-mediated tumour cell destruction and also contributes to NKT-cell cytotoxicity against U937 cells (Takahashi et al, 2000; Voskoboinik and Trapani, 2006). Moreover, Bcl-2 expression can block apoptosis induced by granzyme-B (Pinkoski et al, 2001). We therefore investigated whether sensitization to the effects of the perforin/granzyme-B system could explain the increased target cell apoptosis observed with coexposure to a Bcl-2 inhibitor. In the case of NKT cells, pretreatment with the perforin inhibitor concanamycin-A resulted in no reduction in the killing of U937 cells in the absence of HA14-1, but caused almost complete abrogation of HA14-1-mediated cytotoxicity amplification. One explanation for these results is that Bcl-2 overexpression in the U937 cells caused essentially complete suppression of granzyme-Binduced apoptosis. This was reversed by HA14-1 binding to Bcl-2, resulting in increased killing of U937 cells via the perforin/ granzyme-B mechanism. As perforin inhibition by concanamycinA abrogated almost all of this increase, it follows that the perforin/ granzyme-B system was the predominant pathway affected by the Bcl-2 inhibitor in the cells tested. In the case of $1 \mathrm{H} 3 \mathrm{~T}$-cells, destruction of A02 melanoma cells was mediated almost exclusively via the perforin/granzyme-B system, either in the presence or absence of the Bcl-2 inhibitor. The marked increase in cytotoxicity associated with coexposure to ABT-737 in this model is therefore likely due to sensitization to the pro-apoptotic effects of perforin/granzyme-B. From a mechanistic standpoint, it is significant that the pro-apoptotic $\mathrm{BH} 3$-only protein Bid is cleaved to its active form by granzyme- $B$, allowing it to trigger cytochrome- $c$ release from mitochondria, caspase activation and apoptosis (Ida et al, 2003). Bcl-2 expressed by tumour cells could 
sequester activated Bid (Letai et al, 2002), and therefore block apoptosis in the face of immune cell-derived granzyme-B. However, coexposure to $\mathrm{BH} 3$ mimetic compounds (such as HA14-1 and ABT-737) could potentially displace activated Bid from $\mathrm{Bcl}-2$, and thus promote cell death.

Our results suggest that combining a Bcl-2 inhibitor with clinical immunotherapy may result in enhanced anticancer efficacy. Moreover, Bcl-2 inhibitors may be especially useful in tumours where the perforin/granzyme-B system is the main functional pathway available for target cell killing. For example, FasL and TRAIL do not effectively signal apoptosis in some tumour cells (Mace et al, 2006), and therefore targeting the perforin/granzyme$\mathrm{B}$ mechanism may be essential to immunological antitumour activity in these cases. Effective small-molecule inhibitors of Bcl-2 and related antiapoptosis proteins are now in late preclinical and early clinical development. For example, a phase I study in solid

\section{REFERENCES}

Adams JM, Cory S (1998) The Bcl-2 protein family: arbiters of cell survival. Science 281: $1322-1326$

Banker DE, Groudine M, Norwood T, Appelbaum FR (1997) Measurement of spontaneous and therapeutic agent-induced apoptosis with BCL-2 protein expression in acute myeloid leukemia. Blood 89: 243-255

Campos L, Sabido O, Viallet A, Vasselon C, Guyotat D (1999) Expression of apoptosis-controlling proteins in acute leukemia cells. Leuk Lymph 33: 499-509

Cory S, Vaux DL, Strasser A, Harris AW, Adams JM (1999) Insights from Bcl-2 and Myc: malignancy involves abrogation of apoptosis as well as sustained proliferation. Cancer Res 59: $1685 \mathrm{~s}-1692 \mathrm{~s}$

Cotter FE, Johnson P, Hall P, Pocock C, al Mahdi N, Cowell JK, Morgan G (1994) Antisense oligonucleotides suppress B-cell lymphoma growth in a SCID-hu mouse model. Oncogene 9: 3049-3055

Fischer K, Andreesen R, Mackensen A (2002) An improved flow cytometric assay for the determination of cytotoxic $\mathrm{T}$ lymphocyte activity. J Immunol Methods 259: 159-169

Fulda S, Meyer E, Debatin KM (2002) Inhibition of TRAIL-induced apoptosis by Bcl-2 overexpression. Oncogene 21: 2283-2294

Guseva NV, Taghiyev AF, Rokhlin OW, Cohen MB (2002) Contribution of death receptor and mitochondrial pathways to Fas-mediated apoptosis in the prostatic carcinoma cell line PC3. Prostate 51: 231-240

Ida $H$, Nakashima T, Kedersha NL, Yamasaki S, Huang M, Izumi $Y$, Miyashita T, Origuchi T, Kawakami A, Migita K, Bird PI, Anderson P, Eguchi K (2003) Granzyme B leakage-induced cell death: a new type of activation-induced natural killer cell death. Eur J Immunol 33: $3284-3292$

Jansen B, Schlagbauer-Wadl H, Brown BD, Bryan RN, van Elsas A, Muller M, Wolff K, Eichler HG, Pehamberger H (1998) bcl-2 antisense therapy chemosensitizes human melanoma in SCID mice. Nat Med 4: $232-234$

Kataoka T, Shinohara N, Takayama H, Takaku K, Kondo S, Yonehara S, Nagai K (1996) Concanamycin A, a powerful tool for characterization and estimation of contribution of perforin- and Fas-based lytic pathways in cell-mediated cytotoxicity. J Immunol 156: 3678-3686

Kikuchi A, Nieda M, Schmidt C, Koezuka Y, Ishihara S, Ishikawa Y, Tadokoro K, Durrant S, Boyd A, Juji T, Nicol A (2001) In vitro antitumour activity of alpha-galactosylceramide-stimulated human invariant Valpha24+NKT cells against melanoma. Br J Cancer 85: 741-746

Letai A, Bassik MC, Walensky LD, Sorcinelli MD, Weiler S, Korsmeyer SJ (2002) Distinct BH3 domains either sensitize or activate mitochondrial apoptosis, serving as prototype cancer therapeutics. Cancer Cell 2: $183-192$

Lickliter JD, Wood NJ, Johnson L, McHugh G, Tan J, Wood F, Cox J, Wickham NW (2003) HA14-1 selectively induces apoptosis in Bcl-2overexpressing leukemia/lymphoma cells, and enhances cytarabineinduced cell death. Leukemia 17: 2074-2080

Lin H, Nieda M, Nicol AJ (2004) Differential proliferative response of NKT cell subpopulations to in vitro stimulation in presence of different cytokines. Eur J Immunol 34: 2664-2671

Mace TA, Yamane N, Cheng J, Hylander BL, Repasky EA (2006) The potential of the tumor microenvironment to influence Apo2L/TRAIL induced apoptosis. Immunol Invest 35: 279-296 tumours of GX15-07 (a pan-Bcl-2 family inhibitor developed by Gemin X Biotechnologies, Montreal, Canada) has already commenced. The Abbott Laboratories compound ABT-737 has shown considerable promise in preclinical studies, and clinical trials of this (or related) molecules may follow (Oltersdorf et al, 2005). Consequently, clinical trials of Bcl-2 inhibitory drugs in combination with anticancer immunotherapy may soon be feasible. Bcl-2 inhibition, however, might also induce apoptosis in activated immune cells, and this could limit its application in immunotherapy strategies involving the in vivo activation of antitumour lymphocytes. It is therefore possible that Bcl-2 inhibitors will be most useful in conjunction with adoptive immunotherapy. For example, infusions of immune cells activated by cytokines ex vivo could be combined with a Bcl-2 inhibitor in a temporal sequence similar to that used in the current in vitro study.

Morris MJ, Tong WP, Cordon-Cardo C, Drobnjak M, Kelly WK, Slovin SF, Terry KL, Siedlecki K, Swanson P, Rafi M, DiPaola RS, Rosen N, Scher HI (2002) Phase I trial of BCL-2 antisense oligonucleotide (G3139) administered by continuous intravenous infusion in patients with advanced cancer. Clin Cancer Res 8: 679-683

Nicol A, Nieda M, Koezuka Y, Porcelli S, Suzuki K, Tadokoro K, Durrant S, Juji T (2000) Human invariant valpha24+ natural killer T cells activated by alpha-galactosylceramide (KRN7000) have cytotoxic anti-tumour activity through mechanisms distinct from $\mathrm{T}$ cells and natural killer cells. Immunology 99: 229-234

Nieda M, Nicol A, Koezuka Y, Kikuchi A, Lapteva N, Tanaka Y, Tokunaga K, Suzuki K, Kayagaki N, Yagita H, Hirai H, Juji T (2001) TRAIL expression by activated human $\mathrm{CD} 4(+) \mathrm{V}$ alpha $24 \mathrm{NKT}$ cells induces in vitro and in vivo apoptosis of human acute myeloid leukemia cells. Blood 97: $2067-2074$

Nieda M, Nicol A, Koezuka Y, Kikuchi A, Takahashi T, Nakamura H, Furukawa H, Yabe T, Ishikawa Y, Tadokoro K, Juji T (1999) Activation of human Valpha24NKT cells by alpha-glycosylceramide in a CD1drestricted and Valpha24TCR-mediated manner. Hum Immunol 60: $10-19$

Oltersdorf T, Elmore SW, Shoemaker AR, Armstrong RC, Augeri DJ, Belli BA, Bruncko M, Deckwerth TL, Dinges J, Hajduk PJ, Joseph MK, Kitada S, Korsmeyer SJ, Kunzer AR, Letai A, Li C, Mitten MJ, Nettesheim DG, Ng S, Nimmer PM, O'Connor JM, Oleksijew A, Petros AM, Reed JC, Shen W, Tahir SK, Thompson CB, Tomaselli KJ, Wang B, Wendt MD, Zhang H, Fesik SW, Rosenberg SH (2005) An inhibitor of Bcl-2 family proteins induces regression of solid tumours. Nature 435: $677-681$

Philpott NJ, Turner AJ, Scopes J, Westby M, Marsh JC, Gordon-Smith EC, Dalgleish AG, Gibson FM (1996) The use of 7-amino actinomycin D in identifying apoptosis: simplicity of use and broad spectrum of application compared with other techniques. Blood 87: 2244-2251

Pinkoski MJ, Waterhouse NJ, Heibein JA, Wolf BB, Kuwana T, Goldstein JC, Newmeyer DD, Bleackley RC, Green DR (2001) Granzyme B-mediated apoptosis proceeds predominantly through a Bcl-2-inhibitable mitochondrial pathway. J Biol Chem 276: 12060-12067

Raisova M, Hossini AM, Eberle J, Riebeling C, Wieder T, Sturm I, Daniel PT, Orfanos CE, Geilen CC (2001) The Bax/Bcl-2 ratio determines the susceptibility of human melanoma cells to CD95/Fas-mediated apoptosis. J Invest Dermatol 117: $333-340$

Reed JC (1999) Mechanisms of apoptosis avoidance in cancer. Curr Opin Oncol 11: $68-75$

Skinnider BF, Horsman DE, Dupuis B, Gascoyne RD (1999) Bcl-6 and Bcl-2 protein expression in diffuse large B-cell lymphoma and follicular lymphoma: correlation with 3q27 and 18q21 chromosomal abnormalities. Hum Pathol 30: 803-808

Takahashi T, Nieda M, Koezuka Y, Nicol A, Porcelli SA, Ishikawa Y, Tadokoro K, Hirai H, Juji T (2000) Analysis of human V alpha 24+ CD4+ NKT cells activated by alpha-glycosylceramide-pulsed monocyte-derived dendritic cells. J Immunol 164: 4458-4464

Torigoe T, Millan JA, Takayama S, Taichman R, Miyashita T, Reed JC (1994) Bcl-2 inhibits T-cell-mediated cytolysis of a leukemia cell line. Cancer Res 54: 4851 - 4854 
Velthuis JH, Rouschop KM, De Bont HJ, Mulder GJ, Nagelkerke JF (2002) Distinct intracellular signaling in tumor necrosis factor-related apoptosis-inducing ligand- and CD95 ligand-mediated apoptosis. J Biol Chem 277: $24631-24637$

Voskoboinik I, Trapani JA (2006) Addressing the mysteries of perforin function. Immunol Cell Biol 84: 66-71

Wang JL, Liu D, Zhang ZJ, Shan S, Han X, Srinivasula SM, Croce CM, Alnemri ES, Huang Z (2000) Structure-based discovery of an organic

compound that binds Bcl-2 protein and induces apoptosis of tumor cells. Proc Natl Acad Sci USA 97: 7124-7129

Waters JS, Webb A, Cunningham D, Clarke PA, Raynaud F, di Stefano F, Cotter FE (2000) Phase I clinical and pharmacokinetic study of bcl-2 antisense oligonucleotide therapy in patients with non-Hodgkin's lymphoma. J Clin Oncol 18: 1812-1823

Yuen AR, Sikic BI (2000) Clinical studies of antisense therapy in cancer. Front Biosci 5: D588-593 